\title{
INTERVENSI TURKI DALAM KRISIS SURIAH (2011-2014)
}

\section{Cite as}

Luerdi, L. (2016). Intervensi Turki Dalam Krisis Suriah (2011-2014). International Society, 3(2), 33-50. https://doi.org/10.5281/zenodo.5830875 


\title{
Intervensi Turki dalam Krisis Suriah (2011-2014)
}

\author{
LUERDI \\ Universitas Abdurrab
}

\begin{abstract}
This research aims to explain Turkey's intervention in Syrian crisis due to the perception of threat toward its security or domestic stability. Syrian crisis has directed threat indirectly to Turkey related to the existence of Kurd rebel group Kurdistan Workers Party or PKK's activity in Syria. Syria makes the PKK affiliated to Syrian Kurd group Democratic Union Party or PYD an important actor particularly in northern area of the state during the crisis. Amid the instability caused by armed conflict in Syria, Turkey believes both political and military force of the PKK-PYD's can injure its security or domestic stability now that the PKK still demands either territorial seccession or autonomy for Kurd's southeastern area.The research applies the worldview of international relations realism to describe Turkey's behavior as a state with its power in responding to its surrounding. To strengthen the approach used, the research applies intervention theory which is able to explain the relation of Turkey's intervention to the threat toward its security or domestic stability which it perceives as a vital national interest. Indeed, the result of the research shows a finding that such perception of threat encourages Turkey to commit intervention in Syrian crisis. Turkey's intervention aims to remove the leadership of Syrian current regime with that of Syrian opposition group in which it trusts to be capable of creating stability, controlling and restricting the political and military movement of Kurd groups in Syria.
\end{abstract}

Key words: crisis, threat, security, domestic stability, intervention.

\section{Pendahuluan}

Salah satu peristiwa yang menjadi isu internasional sejak awal 2011 silam adalah revolusi di negara-negara Arab yang dikenal dengan the Arab Spring. Kasus revolusi di Suriah paling banyak menyita perhatian dunia internasional karena tuntutan revolusi yang mulanya untuk pergantian rezim berubah menjadi krisis politik berdarah, konflik bersenjata (armed conflict) dan perang saudara (civil war) antara kelompok oposisi dan rezim Suriah (Bashar al Assad). ${ }^{1}$ Tindakan Suriah yang menggunakan cara-cara kekerasan dalam merespon tuntutan revolusi semakin meningkatkan pemberontakan dari kelompok oposisi yang tergabung dalam Syrian National Council/Coalition (SNC) dan Free Syria Army (FSA).

Benturan kepentingan antar-kekuatan asing berkontribusi pada semakin lambatnya penyelesaian krisis. Rusia, Iran, Cina, Turki, Uni Eropa, Amerika Serikat dan beberapa negara Timur Tengah memiliki kepentingan dalam krisis tersebut. Di antara kekuatankekuatan tersebut, Turki merupakan negara yang paling banyak menerima dampak dari

\footnotetext{
${ }^{1}$ Kelompok oposisi dalam penelitian ini juga sering disebut kelompok pemberontak, sedangkan rezim Suriah beserta sekutunya menyebut kelompok oposisi sebagai teroris.
} 
intervensinya. ${ }^{2}$ Intervensi Turki mendapatkan kecaman dari negara-negara sekutu Suriah dan mulai tidak populis bagi sebagian negara Muslim, namun Turki konsisten untuk terlibat dalam krisis Suriah. Turki merupakan negara yang paling keras mengkritisi kekejaman Suriah dan terang-terangan menghendaki segera berakhirnya rezim penguasa di negara tersebut.

Sebagai kekuatan yang pengaruhnya sedang diperhitungkan baik di kawasan Timur Tengah dan Eropa, Turki merasa perlu untuk melakukan intervensi. Ikhwal intervensi Turki yang tampak adalah kebijakan open-door policy bagi para pengungsi Suriah untuk memasuki wilayahnya. Turki mulai menunjukkan penentangan terbuka terhadap Suriah ketika negara tersebut mulai menggunakan cara-cara represif dan senjata kimia dalam menghadapi kelompok oposisi Suriah yang menyebabkan korban sipil. ${ }^{3}$ Sikap dan protes Turki tersebut berlanjut pada penarikan duta besar dan seluruh staf diplomatiknya dari Suriah.

Posisi Turki di pertemuan beragam dinamika politik dan kepentingan berbagai negara secara geografis dan geopolitik serta meningkatnya kapabilitasnya sebagai aktor regional menjadi landasan untuk mencari legitimasi atas keyakinan bahwa keamanan dan stabilitas internalnya hanya dapat dicapai melalui keamanan dan stabilitas kawasan. ${ }^{4}$ Di balik landasan ini terdapat usaha-usaha yang dimaksudkan untuk menciptakan lingkungan perdamaian, keamanan dan kedamaian berkelanjutan di dalam kawasan dan di luarnya. Seiring dengan terjadinya krisis Suriah, kepentingan untuk menjamin stabilitas domestik dianggap jauh lebih penting ketimbang sekedar menyebarkan soft power dan membatasi ambisi Iran di kawasan Timur Tengah. ${ }^{5}$

Wilayah utara Suriah berbatasan langsung dengan wilayah tenggara Turki yang didiami oleh mayoritas Kurdi Turki. Wilayah tersebut merupakan basis gerakan kelompok pemberontak Kurdi Turki, Kurdistan Workers Party (PKK). Gerakan PKK sulit diatasi karena basisnya menyebar ke negara-negara tetangga Turki. Dalam sejarah pemberontakannya yang dimulai sejak akhir tahun 1970-an, PKK mendapatkan dukungan tidak hanya dari entitas Kurdi dalam wilayah Turki tapi juga dari kekuatan eksternal seperti Uni Soviet, Kurdi Irak, Kurdi Iran, Kurdi Suriah dan termasuk Suriah untuk memperlemah Turki. ${ }^{6}$ Sampai saat ini belum ada kesepakatan damai komprehensif Turki-PKK. Bersamaan dengan keterlibatan Turki dalam krisis Suriah, geliat aktifitas PKK kembali menguat.

Pada awal-awal revolusi Suriah, beberapa kelompok Kurdi Suriah sepakat untuk berada dalam koalisi kelompok oposisi tapi akhirnya keluar dari koalisi tersebut.

\footnotetext{
${ }^{2}$ Doruk Ergun., 'Turkish Views on the Syrian Civil War', 21 January 2014,

$<$ https://www.aspeninstitute.it/aspenia-online/article/turkish-views-syrian-civil-war>, [diakses 19 April 2014].

${ }^{3}$ Ilias I. Kouskouvelis., 'Turkey, Past and Future: The Problem with Turkey's Zero Problems', dalam Middle East Quarterly, Winter 2013, Volume XX, Middle East Forum, hal. 55.

4 'Synopsis of the Turkish Foreign Policy', <http://www.mfa.gov.tr/synopsis-of-the-turkish-foreignpolicy.en.mfa>, [diakses 08 Agustus 2014].

5 'Turkey's Interest in Syrian War', 2014, The Caspian Report, <http://www.youtube.com/turkey's-interest,-insyrian-war/the-caspian-report/>, [diakses 19 April 2014].

${ }^{6}$ Robert Hatem and Mark Dohrmann., 'Ankara's Challenges: Turkey’s Fix for the Kurdish Problem', dalam Middle East Quarterly, Fall 2013, Volume XX, Middle East Forum, hal. 51.
} 
Perubahan sikap tersebut terjadi ketika Suriah mengeluarkan kebijakan pemberian kewarganegaraan kepada etnis Kurdi Suriah dan otonomi kepada wilayah Kurdi di utara Suriah. Kurdi Suriah kemudian dapat mengatur sendiri wilayah utara, sementara kelompok oposisi mengganggap Kurdi Suriah mendukung rezim yang sedang berkuasa. Beberapa pertempuran telah sering terjadi antara FSA dengan kelompok Kurdi Suriah di wilayah tersebut.

Di antara kelompok Kurdi Suriah, Democratic Union Party (PYD) adalah yang paling kuat dan menentang keterlibatan Turki dalam konflik di Suriah. PYD yang dibentuk pada 2003 merupakan sister organization gerakan PKK di Turki.7 PYD merupakan kelompok Kurdi Suriah yang paling kuat menginginkan otonomi yang luas di wilayah Kurdi, tapi tetap berada dalam kedaulatan Suriah. Baik kelompok oposisi dan Turki masih mencurigai agenda ambisius PYD untuk memisahkan wilayah utara dari Suriah.

Turki dan Suriah pernah menandatangani Adana Agreement pada 1998 yang bertujuan untuk meningkatkan kerjasama ekonomi dan keamanan kedua negara. ${ }^{8}$ Dengan adanya kerjasama tersebut, ruang gerak bagi pemberontak PKK dapat dipersempit, hubungan kedua negara menjadi semakin harmonis dan sangat intens melakukan berbagai kerjasama bilateral sampai akhir tahun 2010. Upaya Turki untuk membujuk rezim Suriah agar melepaskan kekuasaannya mengalami kegagalan. Turki akhirnya melakukan tindakan intervensi dalam krisis internal Suriah untuk mengganti rezim yang sedang berkuasa walaupun harus berdampak pada memburuknya hubungan kedua negara.

\section{Rumusan Masalah}

Adapun rumusan masalah yang diangkat dalam penelitian ini adalah: "Mengapa Turki melakukan intervensi untuk mengganti rezim penguasa (Bashar al Assad) dalam krisis Suriah (2011-2014)?"

\section{Kerangka Teoritis}

Tulisan ini menggunakan worldview realisme hubungan internasional dan tingkat analisis negara-bangsa (nation-state analysis). Menurut Stephen Krasner, realisme merupakan teori politik internasional dan merupakan sebuah upaya menjelaskan tingkah laku tiap negara dan karakteristik sistem internasional secara keseluruhan. ${ }^{9}$ Realisme memberikan perhatian utama pada isu ancaman dan keamanan. Negara bangsa merupakan atom dari jagad raya politik internasional, sedangkan aktor lain

\footnotetext{
7 Jamie Dettmer., 'Syria Falls Apart: Kurds Declare Self-Rule, Assad Besieges Aleppo', 14 September 2013, $<$ http://www.thedailybeast.com/articles/2013/11/14/ syria-falls-apart-kurds-declare-self-rule-assad-besiegesaleppo.html>, [diakses 19 April 2014].

${ }^{8}$ Franco Galdini and Pishko Shamsi., 'Syria's Kurds and Turkey', $<$ http://www.jadaliyya.com/pages/index/15078/syria\%E2\%80\%99s-kurds-and-turkey>, [diakses 19 April 2014].

${ }^{9}$ Martin Griffits., Lima Puluh Pemikir Studi Hubungan Internasional, Edisi ke-1, PT.Raja Grafindo Persada, Jakarta, 2001, hal.42.
} 
seperti individu dan organisasi hanya akan bermakna bila terkait dengan suatu negarabangsa 10

Adapun teori yang digunakan dalam penelitian ini adalah teori intervensi. Dalam rangka mencapai tujuan dan memperjuangkan atau mempertahankan kepentingan nasionalnya, suatu negara dapat melakukan berbagai pilihan kebijakan luar negeri, baik melalui saluran diplomatik ataupun melalui saluran ancaman sampai kepada tindakan militer. ${ }^{11}$ Intervensi merupakan salah satu wujud dari pilihan kebijakan dalam interaksi antar-negara. Beberapa cara atau teknik intervensi yang umum dilakukan seperti infiltrasi, mensponsori pemogokan, menciptakan skandal politik, melakukan percobaan kudeta, mengorganisir dan memfasilitasi kelompok pemberontak dalam suatu negara, kegiatan subversif dan lain sebagainya. ${ }^{12}$

Tindakan penetrasi politik atau militer sebagai intervensi bukanlah hal yang baru dalam politik internasional. Sukar bagi suatu negara untuk kurang peduli atau mengambil jarak terhadap revolusi atau krisis politik yang terjadi di negara lain, terutama negara tetangga karena baik revolusi maupun krisis politik tersebut tidak selalu menguntungkan baginya. ${ }^{13}$ Berbagai praktik intervensi yang pernah dilakukan oleh negara-negara dan organisasi internasional seperti NATO dan PBB lazimnya didorong oleh kemelut dalam negeri suatu negara.

Suatu negara melalui pemerintahnya akan mengoptimalkan power dan kapabilitas yang dimiliki untuk mengejar ataupun melindungi kepentingan nasional. Negara memiliki alasan pembenaran atas tindakan yang diambil dalam berinteraksi walaupun dalam bentuk konflik dengan aktor lainnya yang digerakkan oleh kepentingan nasional. S.L. Roy berpendapat pemeliharaan keamanan tampaknya menjadi kepentingan terdepan dalam tujuan politik negara. ${ }^{14}$ Dalam penelitian ini, kepentingan Turki yang ingin diangkat adalah nilai keamanan berupa stabilitas domestiknya yang termasuk dalam kategori core interest.

Krisis politik yang terjadi di Suriah memaksa Turki untuk mempertimbangkan dampak yang diperoleh. Eksistensi rezim dan kebijakan Suriah untuk wilayah Kurdi (utara Suriah), instabilitas dalam negeri Suriah yang tak menentu, dan aktifitas politik dan militer kelompok Kurdi adalah ancaman bagi Turki. Sedangkan letak geografis Turki yang berbatasan langsung dengan Suriah dan dukungan etnis Kurdi pada PKK dapat menguatkan persepsi ancaman tersebut. Bentuk-bentuk ancaman tersebut dapat mengganggu keamanan atau stabilitas domestik Turki. Dengan demikian, Turki merasa perlu untuk memperjuangkan stabilitas domestik tersebut melalui tindakan intervensi.

Tindakan Turki untuk terlibat dalam konflik bersenjata di Suriah merupakan kebijakan yang diambil dengan mempertimbangkan kebutuhan dengan dimensi

\footnotetext{
${ }^{10}$ Mohtar Mas'oed., Studi Hubungan Internasional; Tingkat Analisis dan Teorisasi, Pusat Antar UniversitasStudi Sosial Universitas Gadjah Mada, Yogyakarta, 1989, hal.86.

${ }^{11}$ R. Soeprapto., Hubungan Internasional; Sistem, Interaksi dan Perilaku, PT. Raja Grafindo Persada, Jakarta, 1997, hal. 281.

12 Ibid.,

${ }^{13}$ Ibid., hal. 281-282.

${ }^{14}$ S.L. Roy., Diplomasi, Edisi ke-1, terj. Herwanto dan Mirsawati, Rajawali Pers, Jakarta, 1991, hal. 6.
} 
keamanan berupa stabilitas politik domestik dan juga keamanan daerah perbatasan. Instabilitas di Suriah khususnya di wilayah utara Suriah dapat memberikan efek domino kepada Turki. Kebutuhan akan stabilitas domestik menjadi nilai yang diperjuangkan untuk menjamin keberlangsungan Turki sebagai suatu negara. Elemen yang paling berpengaruh mendorong kebijakan luar negeri negara-negara adalah power. ${ }^{15}$ Dengan power yang dimiliki, Turki berupaya memaksimalkan potensinya untuk menjalankan kebijakan tersebut walau akhirnya harus masuk dalam lingkaran konflik yang terjadi di Suriah dan menerima berbagai konsekuensi dari kebijakan tersebut.

Holsti membagi tindakan intervensi ke dalam enam bentuk, yaitu; (1) campur tangan diplomatik, (2) tindakan politik terselubung, (3) unjuk kekuatan, (4) subversi, (5) perang gerilya terutama yang didukung dan diorganisir dari luar dan (6) intervensi militer. ${ }^{16}$ Dalam praktiknya, negara yang berkepentingan untuk melakukan intervensi tidak selalu melakukan semua teknik intervensi tersebut. Negara bisa saja memilih satu bentuk teknik intervensi atau mengkombinasikan pilihan teknik-teknik intervensi yang ada. Menurut Holsti, berbagai tindakan intervensi tersebut akan tetap menjadi teknik yang penting untuk mempengaruhi, memaksa negara lain dan mengeksploitasi atau menyelesaikan krisis domestik dalam sistem politik yang tidak stabil. ${ }^{17}$

Di antara bentuk-bentuk tindakan intervensi diatas, campur tangan diplomatik terlihat sangat jelas dilakukan oleh Turki dalam krisis Suriah. Campur tangan diplomatik masalah dalam negeri negara lain diartikan ketika pejabat diplomatik atau pemerintahan suatu negara memberikan komentar-komentar terbuka berkaitan dengan proses politik dalam negeri ataupun kebijakan luar negeri negara lain. ${ }^{18}$ Komentar-komentar yang dikeluarkan dapat saja menguntungkan atau merugikan pihak atau negara yang sedang dibicarakan. Dalam tindakan intervensi terhadap krisis Suriah, Turki sering mengecam dan menyudutkan Suriah dengan komentar-komentar tentang kekejaman negara tersebut terhadap rakyat sipilnya dan keengganan rezim penguasa untuk menciptakan keadaan yang lebih baik.

Sedangkan menurut Rosenau, intervensi dapat dibedakan dari tindakan negara karena dua hal; (1) intervensi merupakan serpihan tajam dari bentuk interaksi hubungan yang konvensional; (2) intervensi secara sadar diarahkan untuk mengubah atau mempertahankan tatanan kewenangan politik di negara yang menjadi sasaran tindakan intervensi; kemudian Holsti menambahkan kebanyakan tindakan intervensi dilakukan tanpa izin pemerintah yang berkuasa. ${ }^{19}$ Walaupun intervensi dianggap sebagai tindakan yang mencampuri urusan domestik negara yang berdaulat, negara yang memiliki power akan berupaya mencari alasan untuk membenarkan tindakan intervensi baik yang dilakukan secara diam-diam ataupun terbuka.

\footnotetext{
${ }^{15}$ Lloyd Jensen., Explaining Foreign Policy, Prentice-Hall, Inc. USA, 1982, hal. 264.

${ }^{16}$ R. Soeprapto., op.cit., hal. 290.

${ }^{17}$ Ibid., hal. 303.

${ }^{18}$ Ibid., hal. 290 .

${ }^{19}$ Ibid., hal. 282.
} 
Tindakan intervensi biasanya juga bermakna bias atau sulit lepas dari keberpihakan pada salah satu pihak, misalnya pada pihak pemberontak atau pada pihak pemerintah di suatu negara yang sedang dilanda krisis politik atau revolusi. Richard K. Betts mengatakan kenetralan (impartiality) hanyalah sekedar norma dalam banyak kasus intervensi. ${ }^{20}$ Negara dan organisasi internasional yang terlibat dalam intervensi sangat sulit untuk lepas dari keberpihakan pada salah satu pihak di wilayah yang menjadi sasaran tindakan intervensi tersebut.

Turki melakukan tindakan intervensi dalam krisis Suriah karena krisis tersebut akan berdampak pada kepentingan keamanannya. Krisis yang sedang terjadi di Suriah dapat mengganggu stabilitas domestik Turki bila dikaitkan dengan aktifitas kelompok Kurdi Suriah dan pemberontak PKK. Intervensi yang dilakukan Turki bertujuan untuk mengakhiri rezim yang sedang berkuasa di Suriah. Dalam penelitian ini, Turki melakukan intervensi dalam krisis Suriah secara sadar untuk mengganti tatanan kewenangan politik yang dikendalikan oleh rezim Suriah. Dalam tindakan intervensi tersebut, Turki memberikan dukungan kepada kelompok oposisi.

Dengan melihat teori intervensi yang digunakan, dapat dihubungkan bahwa keamanan merupakan agenda penting bagi Turki. Sebagai negara yang sangat memberikan perhatian pada keamanan domestiknya, Turki memiliki persepsi ancaman dari peristiwa yang terjadi di Suriah. Karena ancaman terhadap keamanan tersebut berasal dari luar teritorialnya, Turki merespon untuk memperjuangkannya melalui kebijakan luar negeri dalam bentuk intervensi. Intervensi Turki bertujuan mengganti rezim penguasa Suriah dan mengupayakan munculnya kepemimpinan baru yang dapat mewujudkan stabilitas di Suriah dan wilayah perbatasan, serta mengontrol dan membatasi ruang gerak politik dan militer kelompok Kurdi di Suriah.

\section{Persepsi Ancaman terhadap Keamanan/Stabilitas Domestik Turki}

\section{Suriah Memberikan Otonomi kepada Wilayah Utara}

Wilayah utara Suriah merupakan wilayah yang didiami oleh mayoritas etnis Kurdi Suriah, jumlahnya mencapai 2 juta jiwa atau sekitar 10 persen dari total penduduk Suriah. ${ }^{21}$ Wilayah utara tersebut berbatasan langsung dengan wilayah tenggara Turki yang juga didiami oleh etnis Kurdi. Kedekatan geografis dan kesamaan etnis tersebut telah menjadi alasan logis bagi kelompok Kurdi Suriah dan Kurdi Turki untuk mengorganisasikan gerakan pemberontakan Kurdistan.

Kebijakan Suriah yang paling mempengaruhi etnis Kurdi adalah pemberian otonomi khususnya dalam bidang politik dan pemerintahan kepada wilayah utara Suriah yang sudah lama mereka idamkan dan perjuangkan. Untuk meyakinkan etnis Kurdi, Suriah mulai menarik pasukan militernya dari wilayah tersebut. Pemberian

\footnotetext{
${ }^{20}$ Richard K. Betts., 'The Delution of Impartial Intervention,' dalam Conflict After the Cold War; Arguments on the Causes of War and Peace, Second Edition, ed. Richard K. Betts, Pearson Education, Inc., USA, 2004, hal. 602.

21 'Syria's Many Battlefields: Islamist Rebels Wage War Against the Kurds', 26 September 2013, $<$ http://world.time.com/2013/09/26/syrias-many-battlefields-islamist-rebels-wage-war-against-the-kurds/>, [diakses 19 April 2014].
} 
otonomi kepada etnis Kurdi merupakan upaya Suriah untuk mengurangi jumlah kekuatan oposisi. Dengan demikian, Suriah dapat mencegah kelompok Kurdi mainstream bergabung dengan pihak oposisi. Kelompok Kurdi juga dapat diandalkan untuk menghadapi kelompok oposisi yang berupaya untuk merebut wilayah utara Suriah.

Setelah keluar dari SNC, berbagai kelompok Kurdi Suriah membentuk badan koordinasi bersama yang bernama National Body for Democratic Change. ${ }^{22}$ Badan koordinasi tersebut merupakan wadah bagi Kurdi Suriah untuk memperjuangkan kepentingan wilayahnya dengan adanya momentum krisis. Kurdi Suriah berhasil merebut lebih banyak daerah di wilayah utara setelah penarikan mundur seluruh pasukan Suriah pada pertengahan 2012.23 Dengan semakin banyaknya daerah-daerah yang mulai dikuasai, Kurdi Suriah menyatakan sebagai penguasa sah wilayah utara Suriah dan kemudian membentuk pemerintahan regional otonomi Kurdi yang bernama Supreme Kurdish Committee (SKC).

Bagi Turki, pemberian otonomi oleh Suriah kepada wilayah Kurdi Suriah dapat menguatkan kembali keinginan Kurdi Turki untuk mendapatkan hal yang sama. PKK yang mengklaim dirinya sebagai representasi etnis Kurdi Turki masih menuntut otonomi khusus kepada Turki bila negara tersebut tidak bersedia melepaskan wilayah Kurdinya. Turki tetap enggan memberikan otonomi seperti yang diperjuangkan oleh PKK karena negara tersebut memiliki konsep kebangsaan di mana semua warga negaranya baik itu etnis Turki, Kurdi, Roma, Yunani dan keturunan etnis lainnya memiliki hak dan perlakuan yang sama sehingga tidak diperlukan perlakuan istimewa terhadap kelompok etnis tertentu. ${ }^{24}$

Otonomi bagi etnis tertentu hanya akan menjadi pemicu disintegrasi Turki. Tuntutan otonomi dapat memicu menggeliatnya kembali pemberontakan dan aksi-aksi teror yang dilakukan oleh PKK sehingga dapat berdampak pada instabilitas domestik Turki. Mundurnya gerilyawan PKK dari Turki pada 2013 lalu menuju wilayah Irak dan Suriah tidak berarti menghentikan aktifitas politik dan militer kelompok pemberontak tersebut, malahan membuat Turki semakin sulit untuk mengatasinya.

\section{Peningkatan Kekuatan dan Pengaruh PYD di Wilayah Utara}

PYD juga sering dianggap sebagai cabang PKK di Suriah karena dibentuk oleh PKK setelah Suriah memukul mundur sebagian besar gerilyawan PKK keluar dari teritorialnya sebagai implementasi butir Adana Agreement. Bagi Turki, PKK dan PYD memiliki agenda internasional jangka panjang yaitu mewujudkan negara Kurdistan independen yang wilayahnya meliputi utara Suriah, tenggara Turki, utara Irak, dan timur Iran. Kecurigaan tersebut dapat dilihat dari aktifitas politik PYD yang menjalin

\footnotetext{
${ }^{22}$ John Caves., 'Syrian Kurds and the Democratic Union Party (PYD)', Backgrounder 06 December 2012, USA, Insitute for the Study of War (ISW), hal. 3, <https://www.understandingwar.org /sites/default/files/Backgrounder_SyrianKurds.pdf>, [diakses 25 Desember 2014].

${ }^{23}$ Jamie Dettmer., loc.cit.

${ }^{24}$ Pernyataan PM Turki Recep Tayyip Erdogan. 'Turkey’s Role in Middle East', Talk to Aljazeera,

$<$ http://www.aljazeera.com/talk-to-aljazeera>, [diakses 19 April 2014].
} 
hubungan dengan Kurdi Irak selain menjaga hubungan erat dengan PKK. Turki menilai keinginan pembentukan otonomi khusus di utara Suriah menjadi batu loncatan untuk mewujudkan agenda ambisius tersebut.

Suriah membiarkan PYD mengontrol keamanan wilayah utara. Efektifitas PYD dalam menguasai wilayah tersebut didukung oleh kekuatan sayap militernya yang dikenal dengan People's Protection Unit (YPG) dan Women's Protection Unit (YPJ). PYD menyatakan telah memiliki sebanyak 50.000 pejuang Kurdi pada pertengahan $2014 .^{25}$ Sebelum terjadinya krisis, gerilyawan PYD tidak dapat bergerak secara bebas karena intelijen dan pasukan Suriah senantiasa mengawasi wilayah utara. Aktifitas politik dan militernya bersifat underground dan cukup sulit untuk menjalankan organisasinya dengan baik. Setelah Suriah memberikan otonomi, PYD mulai mendapatkan kemudahan dan sangat leluasa dalam mengorganisir kekuatannya bahkan meyakinkan banyak milisi Kurdi Suriah untuk bergabung atau berafiliasi dengannya.

PYD mendeklarasikan wilayah otonomi utara suriah secara unilateral pada tahun 2012. ${ }^{26}$ Deklarasi tersebut dikecam oleh kelompok oposisi dan Turki kerena dapat menyebabkan instabilitas Suriah yang lebih buruk dan menggagalkan revolusi rakyat Suriah. Kelompok oposisi dan Turki menginginkan PYD bersama-sama menurunkan rezim Suriah dari kekuasaan dan kemudian membangun pemerintahan baru yang akan memperlakukan seluruh rakyat Suriah tanpa diskriminasi.

Turki berupaya meyakinkan PYD untuk bergabung dengan kelompok oposisi demi kepentingan seluruh rakyat Suriah, tidak hanya kepentingan Kurdi Suriah. Turki juga menginginkan PYD memutus hubungan dengan PKK. Sampai saat ini, komunikasi politik antara Turki dan PYD tidak pernah menemui kesepakatan. PYD tetap menginginkan wilayah utara Suriah dikontrol oleh Kurdi Suriah melalui pemerintahan sendiri dengan status otonomi yang telah diberikan oleh Suriah. PYD juga menolak untuk bergabung dengan kelompok oposisi untuk menghadapi rezim Suriah dan bertekad untuk mensterilkan wilayah utara Suriah dari kekuatan-kekuatan asing termasuk pasukan oposisi (FSA).

Popularitas dan prestasi PYD di utara Suriah mendapatkan simpati dari komunitas etnis Kurdi, tidak hanya di dalam tapi juga di luar Suriah. ${ }^{27}$ Dengan demikian, dukungan terhadap PYD mulai bertambah dari komunitas Kurdi negara-negara tetangga. PYD juga mampu meyakinkan beberapa kelompok Kurdi Suriah untuk membentuk pemerintahan regional Kurdistan di wilayah utara Suriah pasca deklarasi sebagai wilayah otonom. Deklarasi pembentukan pemerintahan tersebut ditandatangi oleh berbagai kelompok Kurdi Suriah yang wilayahnya meliputi propinsi Qamishli, Afrin, dan Kobani. ${ }^{28}$

\footnotetext{
25 'Kurdish People's Protection Unit (YPG)', <http://www.globalsecurity.org/military/world/para/ypg.htm>, [diakses 01 Desember 2015].

${ }^{26}$ Anne Laure Barbosa., 'A Powerful Illusion: Syrian Kurds and the Challenges to Their Autonomy', 20

November 2013, <http://www.edinburghint.com/services/advisory/recent-analysis/a-powerful-illusion-syrian-

kurds-and-the-challenges-to-their-autonomy/>, [diakses 31 Desember 2014].

${ }^{27}$ Franko Galdini dan Pishko Shamsi., loc.cit.,

${ }^{28}$ Namo Abdulla., 'The rise of Syria's Kurds', 23 January 2014,

$<$ http://www.aljazeera.com/indepth/opinion/2014/01/rise-syria-kurds201412353941189707.html>, [diakses 09 Agustus 2014].
} 
Dalam praktiknya, PYD cenderung bersikap otoriter dan mengenyampingkan kekuatan kelompok Kurdi lainnya. PYD mampu mendominasi semua kelompok Kurdi Suriah, mengontrol sebagian besar milisi Kurdi Suriah, mendapatkan popular support yang signifikan dan memiliki organisasi yang efektif. ${ }^{29}$ Kemampuan politik dan militer PYD tidak dapat dipisahkan dari peran PKK. Turki meyakini bahwa PKK memiliki peran dalam mewujudkan ambisi PYD di utara Suriah dan kemudian akan berlanjut ke wilayah tenggara Turki.

\section{Suriah Membiarkan PKK Beroperasi di Wilayah Utara}

Momentum krisis Suriah memudahkan PKK memasuki wilayah utara Suriah baik dari Turki maupun dari Irak. Suriah cenderung membiarkan pergerakan PKK terlebih lagi ketika negara tersebut menarik pasukannya dari wilayah tersebut. Gerilyawan PKK memang sudah ada dan membangun basis pemberontakan di wilayah utara Suriah yang dibantu oleh PYD sebelum krisis, namun tidak seleluasa seperti selama krisis berlangsung. Suriah memiliki kepentingan terhadap keberadaan PKK karena kelompok tersebut bersama PYD mampu menghadapi kelompok oposisi.

Kelompok oposisi dan Turki meyakini bahwa Suriah membantu perlengkapan persenjataan dan informasi intelijen kepada PKK dan PYD. Kurdish National Council (KNC) yang merupakan rival PYD juga menuduh kedua kelompok tersebut memiliki hubungan dengan rezim Suriah. ${ }^{30}$ Akses senjata yang lebih lengkap yang dimiliki oleh PYD dan PKK ketimbang kelompok Kurdi lainnya menguatkan kecurigaan tersebut.

PKK terus melakukan perjuangan bersenjata untuk mendapatkan tujuan politik dengan memasukkan kepentingannya dalam komunitas Kurdi Suriah. Lebih jauh lagi dalam tataran taktik, krisis Suriah memberikan keuntungan militer kepada PKK dalam mengkampanyekan prinsipnya menghadapi Turki dengan bantuan PYD, sedangkan di sisi lain PKK dapat membantu mempromosikan PYD di dalam Suriah. ${ }^{31}$

Turki menuduh Suriah berupaya mendestabilisasi Turki dengan menyerahkan daerah-daerah Kurdi Suriah di bawah kontrol PKK. ${ }^{32}$ PKK dapat melakukan konsolidasi dan meningkatkan kekuatan politik dan militernya setelah mengambil alih daerahdaerah tersebut dengan mudah bersama PYD. Lebih jauh lagi, Turki menuding Suriah memanfaatkan PKK melalui PYD untuk menyerang Turki sebagai balasan atas dukungannya terhadap kelompok oposisi.

Sejak keterlibatan PKK dalam krisis tersebut, sejumlah serangan yang dilakukan oleh PKK di Turki meningkat. Bom mobil yang terjadi di salah satu kota Turki, Gazientep yang merupakan tempat utama bagi para pengungsi Suriah, pada 20 Agustus 2012

\footnotetext{
${ }^{29}$ John Caves., op.cit, hal. 1.

${ }^{30}$ Ibid., hal. 2.

31 Ibid.,

${ }^{32}$ Pernyataan PM Turki, Recep Tayyip Erdogan. Ibid., hal. 2.
} 
diyakini dilakukan oleh PKK dengan bantuan inteligen Suriah. ${ }^{33}$ Turki menuding PKK karena memiliki bukti yang cukup untuk mengalamatkan aksi pengeboman tersebut. PKK sering terlibat dalam serangkaian aksi pengeboman yang terjadi di Turki sejak awal pemberontakannya. PKK dapat dengan mudah mengakses wilayah Kurdi Suriah karena sebagian milisi PKK merupakan etnis Kurdi Suriah. International Crisis Group telah memperkirakan sekitar sepertiga dari pejuang PKK merupakan etnis Kurdi Suriah, sehingga tidaklah sulit bagi PKK untuk beroperasi di antara populasi Kurdi di Suriah. ${ }^{34}$

PKK dapat memperoleh keuntungan dengan menggunakan wilayah Suriah untuk merencanakan dan melakukan serangan di Turki. PKK juga dapat melakukan latihan militer bagi para milisinya tanpa harus merasa khawatir pada rezim Suriah. PKK telah merebut beberapa daerah di utara Suriah yang letaknya sangat berdekatan di perbatasan Turki dan juga daerah yang berada di dalam wilayah Turki. Pada Juli 2012, Turki melancarkan serangan militer untuk merebut kembali kota Semdinli, di propinsi Hakkari dari PKK. PKK juga melakukan penculikan terhadap anggota parlemen Turki di propinsi Tunceli pada Agustus dan menyerang wajib militer Turki di propinsi Bingol pada September di tahun yang sama. ${ }^{35}$

\section{Instabilitas Suriah dan Wilayah Kurdi (Utara)}

Krisis Suriah menyebabkan ketidakpastian (uncertainty) di kawasan dan negara-negara tetangganya, termasuk Turki khususnya berkaitan dengan masalah keamanan. Sejak awal krisis, Turki berupaya untuk terlibat menyelesaikan konflik agar tidak semakin memburuk. Memburuknya stabilitas di Suriah akan berdampak pada stabilitas wilayah utara Suriah yang didiami oleh etnis Kurdi Suriah. Konflik bersenjata selama krisis terjadi hampir menyebar ke seluruh wilayah Suriah termasuk wilayah yang berbatasan langsung dengan Turki.

Turki sangat memberikan perhatian pada situasi yang terjadi di utara Suriah karena dari wilayah tersebutlah serangan dan aksi teror terhadap Turki dilancarkan oleh pemberontak PKK. Turkipun telah menempatkan pasukannya di beberapa titik di perbatasan Turki-Suriah sejak pembentukan pemerintahan otonomi regional Kurdi Suriah. Instabilitas tersebut dapat ditandai dengan konflik bersenjata yang sering terjadi di wilayah Kurdi dan Suriah lainnya. Sejak musim panas 2013 saja, telah ada lebih dari 40 peristiwa pengeboman, termasuk serangan bom bunuh diri. ${ }^{36}$ Kekerasan dan instabilitas di wilayah utara juga semakin menambah jumlah pengungsi akibat konflik dari etnis Kurdi.

Turki menganggap krisis suriah memberikan ancaman secara tidak langsung terhadap keamanan atau stabilitas domestiknya karena letak geografisnya yang berdekatan dengan Suriah dan terlebih lagi keberadaan pemberontak PKK yang masih menjadi masalah dalam negerinya. Persepsi ancaman yang dimiliki oleh Turki semakin

\footnotetext{
${ }^{33}$ Ibid., hal. 7.

34 Ibid.,

35 Ibid.,

36 'Kurdish People's Protection Unit (YPG)', loc.cit.,
} 
besar setelah PYD dan PKK menjadi kekuatan utama yang mengendalikan wilayah otonomi Kurdi Suriah.

\section{Intervensi Turki dalam Krisis Suriah}

\section{Campur Tangan Diplomatik dan Kebijakan Open-door Policy}

Tindakan represif militer Suriah terhadap kelompok oposisi mendorong terjadinya konflik bersenjata yang tidak bisa dihindari dan menciptakan chaos di dalam negeri Suriah. Tuntutan kelompok oposisi yang sebelumnya diekspresikan hanya melalui demonstrasi damai berubah menjadi perlawanan bersenjata. Turki mulai menampakkan penentangan terhadap Suriah setelah negara tersebut menerapkan kebijakan militerisasi terhadap kelompok oposisi beserta para pendukungnya. Sikap tersebut diikuti dengan kebijakan buka pintu (open-door policy) untuk para pengungsi Suriah yang berada di bawah ancaman kekerasan bersenjata. Turki menjadi negara pertama yang bersedia memberikan perlindungan dan bantuan kemanusian kepada rakyat Suriah pada April 2011.37

Bagi Suriah, tindakan Turki yang membuka perbatasannya bagi para pengungsi merupakan bentuk intervensi negara tersebut dalam masalah domestiknya. Suriah meyakini bahwa para anggota kelompok oposisi juga bergabung dengan ribuan pengungsi. Pembukaan perbatasan Turki semakin memudahkan kelompok oposisi keluar dan masuk Suriah untuk menghadapi militer Suriah. Suriah telah mengancam Turki agar tidak membiarkan kelompok oposisi memasuki wilayah Turki. Pada akhir 2014, jumlah pengungsi Suriah yang berada di Turki mencapai 1,5 juta jiwa. ${ }^{38}$

Bagi Turki, kebijakan open-door policy bagi para pengungsi Suriah juga dimaksudkan untuk mengundang perhatian dunia internasional bahwa krisis yang terjadi di Suriah bukan semata masalah domestik suatu negara tapi masalah internasional yang membutuhkan intervensi. Turki juga ingin menunjukkan bahwa rezim dan militer Suriah telah melakukan kejahatan perang terhadap rakyat sipil yang harus segera dihentikan. Sejak Suriah menggunakan kekerasan dalam menghadapi kelompok oposisi, Turki telah sering menunjukkan penolakan dan cenderung melakukan campur tangan diplomatik melalui komentar-komentar para pejabat resmi negara tersebut yang bertujuan mengkritik dan menyudutkan Suriah.

\section{Dukungan terhadap Kelompok Oposisi Suriah}

Sejak awal krisis di Suriah, Turki telah memberikan dukungan kepada kelompok opisisi yang menuntut revolusi dan pergantian rezim. Dukungan politik yang diberikan Turki dapat terlihat ketika pembentukan Free Syrian Army (FSA) dan Syrian National Council (SNC). Turki memfasilitasi pembentukan kedua badan tersebut untuk menghadapi

\footnotetext{
${ }^{37}$ Asli Ilgit and Rochelle Davis., 'The Many Roles of Turkey in the Syrian Crisis', January 28, 2013, $<$ http://www.merip.org/mero/mero012813>, [diakses 30 November 2014].

38 'Erdoğan furious with US, adds al-Assad condition', March 3, 2015,

$<$ http://www.hurriyetdailynews.com/erdogan-furious-with-us-adds-al-assadcondition.aspx?PageID=238\&NID=73192\&NewsCatID=409>, [diakses 03 Maret 2015].
} 
rezim Suriah. Turki mengizinkan wilayahnya digunakan oleh kelompok oposisi untuk mendirikan dan menjalankan kantor serta media center-nya.

FSA dibentuk pada 29 Juli 2011 di Antakya, Turki. FSA merupakan koalisi pasukan anti-rezim Suriah yang diorganisir sebagai sayap militer menghadapi militer Suriah. Sedangkan SNC dibentuk pada 23 Agustus 2011 di Istambul, Turki. SNC menjadi badan koordinasi atau pemerintahan sementara yang dijalankan oleh kelompok oposisi sebagai tandingan pemerintahan rezim yang sedang berkuasa. Setahun kemudian, SNC bersama kelompok anti-rezim lainnya membentuk Syria National Coalition (SNC) sebagai badan perjuangan rakyat Suriah yang lebih representatif.

Dalam praktiknya, FSA berafiliasi dengan SNC dan koalisi kedua badan tersebut sering dikenal dengan the National Coalition of Syrian Revolutionary and Opposition Forces. FSA-SNC merupakan gabungan dari berbagai kelompok anti-rezim Suriah seperti kelompok Islamist, nasionalist, sebagian kecil Kurdi Suriah dan tentara Suriah yang membelot. Tidak sekedar memfasilitasi pembentukan dan operasionalisasi FSASNC di dalam wilayahnya, Turki juga memfasilitasi berdirinya camp militer bagi FSA untuk mengorganisir atau merencanakan aksi militer dan melakukan pelatihan militer bagi pasukannya.

Dua camp militer yang telah dapat diakses media adalah camp 'nerve center' dan camp Reyhanli. ${ }^{39}$ Camp 'nerve center' atau the secret Middle East-run 'nerve centre' berada di kota Adana, perbatasan Turki dan Suriah dan dijadikan pusat militer utama kelompok oposisi. Camp militer Reyhanli juga berada di dekat perbatasan Turki-Suriah dan merupakan camp militer khusus bagi para tentara Suriah yang membelot dan bergabung dengan FSA. Selain memfasilitasi dan menjaga camp militer kelompok oposisi Suriah, Turki memperlonggar bahkan membuka akses keluar-masuk perbatasan yang berada di wilayahnya bagi kelompok oposisi dalam menghadapi militer Suriah. Seperti halnya dengan camp militer kelompok oposisi, pasukan Turki juga menjaga dan mengamankan pintu perbatasan yang dilewati oleh pasukan oposisi tersebut.

Di forum internasional, Turki juga telah beberapa kali memberikan dukungan moral pada kelompok oposisi Suriah dalam upaya mengganti rezim yang sedang berkuasa. Dalam sebuah pidato pertemuan Organisasi Kerjasama Islam (OKI) di Djibouti tahun 2012, Turki kembali menegaskan pengakuan resminya terhadap Syrian National Coalition (SNC) sebagai representasi legitimate rakyat Suriah. ${ }^{40}$ Pengakuan yang diberikan Turki tersebut juga diikuti oleh negara-negara Arab dan barat. Dalam krisis Suriah, kelompok oposisi yang didukung oleh Turki tidak hanya menghadapi militer Suriah, tapi juga menghadapi kelompok Kurdi yaitu PYD dan PKK untuk mempertahankan integrasi negara Suriah.

\footnotetext{
39 'Secret Turkish nerve center leads aid to Syria rebels', July 27, 2012,

$<$ http://www.reuters.com/article/2012/07/27/us-syria-crisis-centre-idUSBRE86Q0JM20120727>, 'Inside Free Syrian Army's Headquarters in Turkey', August 22, 2012, <http://www.almonitor.com/pulse/tr/politics/2012/08/inside-the-free-syrian-armys-turkish-hq.html>, [diakses 10 Maret 2015]. 40 'Turks Grant Recognition to Coalition of Syrians', November 15, 2012, $<$ http://www.nytimes.com/2012/11/16/world/middleeast/turkey-recognizes-new-syrian-rebel-group-aslegitimate-leader-of-syria.html>, [diakses 10 Maret 2015].
} 


\section{Diplomasi terhadap Kekuatan Barat dan Internasional}

Dalam melakukan intervensi, Turki berupaya melakukan pendekatan diplomasi kepada kekuatan barat dan internasional. Sebagai salah satu anggota North Atlantic Treaty Organization (NATO), Turki berupaya untuk membujuk dan meyakinkan Amerika Serikat dan Uni Eropa untuk memberikan perhatian pada krisis politik dan kemanusian yang terjadi di Suriah, serta mendukung kelompok oposisi dan menekan rezim yang sedang berkuasa di negara tersebut. Melalui keberadaan sekutunya di Dewan Keamanan (DK) PBB, Turki mendorong agar krisis Suriah menjadi agenda pembahasan penting dalam organisasi tersebut.

DK PBB telah beberapa kali membicarakan krisis Suriah dan merancang draft resolusi sebagai respon dari krisis tersebut, mulai dari sanksi yang akan diberikan pada Suriah, investigasi internasional terhadap kejahatan kemanusian di Suriah, sampai pada upaya membawa Suriah ke International Criminal Court (ICC). ${ }^{41}$ Walaupun demikian, upaya DK PBB untuk melakukan intervensi selalu gagal karena sekutu Suriah, yaitu Rusia dan Cina selalu memveto setiap resolusi yang telah dirancang sejak tahun 2011.

Diplomasi yang dilakukan Turki kepada kekuatan barat juga dimaksudkan agar intervensi militer menjadi pilihan dalam menyelesaikan krisis Suriah. Turki menilai hanya dengan intervensi militerlah kekejaman rezim di Suriah benar-benar dapat dihentikan, namun negara tersebut tidak ingin bertindak sendirian. Bagi Turki, rezim yang sedang berkuasalah yang menjadi sumber masalah dari konflik yang berkepanjangan di Suriah. Turki bersedia menyediakan fasilitas militernya dan mengerahkan kekuatan militernya untuk menyelesaikan krisis Suriah bila intervensi militer tersebut dilakukan secara kolektif atau di bawah mandat PBB. Keinginan Turki tersebut belum dapat terwujud karena kekuatan barat khususnya Amerika Serikat masih enggan untuk melakukan intervensi militer di Suriah.

Turki juga aktif menjadi anggota Friends of Syria Group (FSG) yang dibentuk pada tahun 2012 sebagai respon penggunaan veto oleh Rusia dan Cina terhadap resolusi DK PBB untuk krisis Suriah. FSG merupakan kelompok negara yang berkepentingan di Suriah dan memantau perkembangan situasi di negara tersebut. Kelompok negara tersebut dibentuk selain untuk membantu korban krisis, juga untuk mendukung kelompok oposisi dan menekan rezim Suriah.

Pertemuan FSG yang pertama dihadiri oleh 70 negara, namun pada 2013 hanya tersisa 11 negara, yaitu Inggris, Mesir, Perancis, Jerman, Italia, Jordania, Qatar, Saudi Arabia, Turki, Uni Emirat Arab dan Amerika Serikat. ${ }^{42}$ Turki menjadi tuan rumah pertemuan kedua kelompok negara tersebut pada tahun 2012. Melalui FSG, Turki tetap meyakinkan bahwa perhatian dunia internasional menjadi penting untuk krisis yang

\footnotetext{
${ }^{41}$ Russia, China veto UN resolution on sending Syria crisis to ICC, May, 23, 2014,

$<$ http://www.france24.com/en/20140522-russia-china-veto-un-resolution-sending-syria-crisis-internationalcriminal-court/>, [diakses 12 Maret 2015].

42 'Diplomats meet in UK to discuss Syria crisis', October 22, 2013,

$<$ http://www.aljazeera.com/news/middleeast/2013/10/diplomats-meet-uk-discuss-syria-crisis-

2013102272528648677.html>, [diakses 12 Maret 2015].
} 
terjadi di Suriah karena krisis tersebut bukanlah sekedar masalah internal suatu negara. Turki juga tetap meyakini bahwa pergantian rezim merupakan solusi tepat dalam menghentikan krisis.

\section{Keterlibatan dalam Konferensi Jenewa}

Konferensi Jenewa (Geneva conference) merupakan pertemuan internasional yang dilakukan khusus untuk membahas perkembangan situasi yang terjadi di Suriah dan bertujuan untuk mencari kemungkinan jalan keluar atau penyelesaian krisis melalui solusi politik. Konferensi tersebut dilatarbelakangi oleh situasi di Suriah yang semakin memburuk dan pelanggaran hak asasi manusia yang terjadi secara massif. Turki termasuk negara yang aktif dalam mendorong terlaksananya konferensi tersebut.

Konferensi Jenewa I (Geneva I) dilaksanakan pada 30 Juni 2012 di Swiss. Pertemuan tersebut pada dasarnya merupakan pertemuan the Action Group for Syria yang disponsori oleh PBB dan negara-negara Liga Arab, termasuk anggota tetap DK PBB (P5), Uni Eropa dan Turki. ${ }^{43}$ Pertemuan tersebut menghasilkan keputusan perlunya pembentukan suatu badan transisi pemerintahan yang wewakili seluruh elemen politik di Suriah. Turki menilai rekomendasi berupa pembentukan pemerintahan transisi akan mampu mendorong terciptanya stabilitas di negara tersebut. Konferensi Jenewa I ternyata tidak efektif dalam menyelesaikan krisis karena pihak-pihak yang berkonflik, yaitu kelompok oposisi dan rezim Suriah tidak dilibatkan dalam konferensi tersebut. Lagi pula, Suriah tidak berminat membentuk badan pemerintahan transisi seperti yang direkomendasikan.

Kegagalan konferensi Jenewa I mendorong terlaksananya konferensi Jenewa II (Geneva II) pada 22-31 Januari 2014, sedangkan pertemuan putaran keduanya dilaksanakan pada 10-15 Februari 2014. Berbeda dengan konferensi sebelumnya yang tidak melibatkan elemen-elemen intenal Suriah, konferensi Jenewa II merupakan pertemuan untuk melakukan negosiasi antara kelompok oposisi dan rezim Suriah, difasilitasi oleh PBB dengan melibatkan pihak-pihak yang telah mengikuti konferensi Jenewa I. Turki berupaya meyakinkan kelompok oposisi untuk menghadiri konferensi tersebut dan tetap memberikan dukungannya.

Dalam konferensi Jenewa II, Turki tidak sekedar mengkampanyekan perlunya pembentukan badan transisi di Suriah tapi juga menegaskan perlunya pergantian rezim di negara tersebut. Turki menyatakan bahwa keberadaan rezim yang sedang berkuasa di Suriah hanya akan memperpanjang konflik bersenjata, yang tidak hanya mengancam rakyat Suriah tapi juga stabilitas regional dan keamanan dalam wilayahnya. Bagi Turki, krisis Suriah merupakan masalah rezim sehingga solusi utamanya terletak pada rezim.

Seperti halnya konferensi Jenewa I, konferensi Jenewa II yang juga dilaksanakan di markas PBB tersebut dinilai sia-sia karena tidak menghasilkan satupun keputusan. Kelompok oposisi dan negara-negara pendukungnya, termasuk Turki menginginkan

\footnotetext{
${ }^{43}$ Richard Reeve, 'Geneva II: prospects for a negotiated peace in Syria', 29 November 2013, $<$ https://www.opendemocracy.net/opensecurity/richard-reeve/geneva-ii-prospects-for-negotiated-peace-insyria>, [diakses 15 Maret 2015].
} 
solusi politik yang ditandai dengan pergantian rezim dan pembentukan badan pemerintahan transisi di Suriah sampai terlaksananya pemilihan umum nasional. Sementara Suriah dan sekutunya menolak tuntutan tersebut dan menginginkan solusi politik dari dalam Suriah tanpa intervensi pihak-pihak luar. ${ }^{44}$

\section{Penolakan terhadap Pemilihan Presiden Suriah}

Suriah memutuskan untuk melaksanakan pemilihan presiden pada 03 Juni 2014. Pemilihan presiden tersebut merupakan peristiwa politik pertama kali dalam sejarah politik domestik Suriah sejak keluarga Assad memegang kendali terhadap Suriah. ${ }^{45}$ Sebelumnya presiden yang berkuasa dapat dengan mudah melanjutkan periode kepemimpinan berikutnya hanya melalui referendum. Kelompok oposisi Suriah menolak pemilihan presiden tersebut karena tidak representatif dan illegitimate. Pemilihan tersebut dilaksanakan di tengah-tengah konflik bersenjata di mana setengah rakyat Suriah tidak dapat memberikan suara mereka. Rezim Suriah juga melarang tokoh-tokoh oposisi untuk berpartisipasi sebagai kandidat presiden Suriah.

Turki bersama PBB, Amerika Serikat, Uni Eropa dan negara-negara Arab mengecam pelaksanaan pemilihan presiden tersebut karena dianggap bertentangan dengan upaya mencari solusi politik untuk menghentikan krisis. ${ }^{46}$ Turki menilai pemilihan presiden tersebut sekedar formalitas untuk memberikan jalan kepada rezim yang sedang berkuasa untuk memperpanjang kepemimpinanannya. Turki dengan jelas menyatakan menolak mengakui pemilihan presiden tersebut beserta hasilnya. Sebaliknya Turki tetap mendukung terbentuknya badan pemerintahan transisi Suriah yang ditandai dengan mundurnya rezim penguasa, sampai dilaksanakannya pemilihan nasional yang diikuti oleh semua elemen politik di Suriah.

\section{Simpulan}

Krisis Suriah telah mendorong munculnya persepsi ancaman secara tidak langsung bagi keamanan atau stabilitas domestik Turki, khususnya berkaitan dengan keberadaan PKK dan PYD. Kedua kelompok tersebut telah menjadi aktor berpengaruh selama berlangsungnya krisis, khususnya di wilayah yang didiami oleh etnis Kurdi. Kebijakan rezim yang sedang berkuasa di Suriah selama krisis berlangsung telah menaikkan bargaining position kelompok Kurdi (PKK-PYD).

Keamanan atau stabilitas domestik merupakan syarat utama bagi Turki untuk menjamin keutuhan integrasi wilayahnya serta melanjutkan pembangunan berkelanjutan dan kesejahteraan bagi warga negaranya. Keamanan atau stabilitas juga

\footnotetext{
44 'Geneva talks: Progress towards peace?', Inside Syria Aljazeera, 02 February 2014, $<$ http://www.aljazeera.com/programmes/insidesyria/2014/02/geneva-talks-progress-towards-peace2014211440978831.html>, [diakses 07 September 2014].

45 'Will elections in Syria make any difference?', Inside Syria Aljazeera, 26 April 2014, $<$ http://www.aljazeera.com/programmes/insidesyria/2014/04/will-elections-syria-make-any-difference2014426173429172730.html>, [diakses 07 September 2014].

46 'Political Settlement becomes Obsolete after the Syrian Presidential Elections', June 18, 2014,

$<$ http://english.dohainstitute.org/release/92316048-a000-4b3e-9057-1c8323f8a8ca>, [diakses 15 Maret 2015].
} 
dibutuhkan agar ambisi Turki untuk menjadi aktor regional yang berpengaruh di Timur Tengah baik secara ekonomi, politik, militer dan sosio-budaya dapat diwujudkan. Turki perlu merespon segala bentuk ancaman tidak hanya yang berasal dari dalam, tapi juga yang berasal dari luar wilayahnya. Eksistensi rezim Suriah yang sedang berkuasa semakin memperkuat kelompok Kurdi yang akan berdampak buruk bagi Turki. Pergantian pemimpin di Suriah dianggap dapat menghilangkan segala bentuk ancaman bagi Turki yang diperjuangkan melalui tindakan intervensi.

Turki telah memberikan perhatian serius terhadap intervensinya sejak 2011 yang lalu, tetapi kebijakan tersebut nampaknya belum menunjukkan keberhasilan. Pada awalnya, Turki menganggap intervensi yang dilakukan dalam krisis Suriah akan mampu mengganti rezim yang sedang berkuasa dengan cepat, apalagi dengan adanya dukungan dari kekuatan barat. Sebaliknya krisis Suriah masih tetap berlanjut tanpa adanya perubahan yang signifikan. Semakin lama konflik berlangsung, kondisi di Suriah semakin tidak menentu dan aktor-aktor yang terlibat konflik bersenjatapun semakin bertambah. Munculnya berbagai kelompok armed islamist group seperti Islamic State (IS) di Suriah semakin memperumit krisis dan mempersulit kelompok oposisi dalam menguasai wilayah-wilayah di Suriah. Di sisi lain, kelompok Kurdi di Suriah khususnya PYD telah mendapatkan simpati dari dunia internasional dalam menghadapi IS. 


\section{Daftar Pustaka}

'Diplomats meet in UK to discuss Syria crisis', October 22, 2013, <http://www.aljazeera.com/news/middleeast/2013/10/diplomats-meet-ukdiscuss-syria-crisis-2013102272528648677.html>, (diakses 12 Maret 2015).

'Erdoğan furious with US, adds al-Assad condition', March 3, 2015, <http://www.hurriyetdailynews.com/erdogan-furious-with-us-adds-al-assadcondition.aspx?PageID=23>, (diakses 03 Maret 2015).

'Geneva talks: Progress towards peace?', Inside Syria Aljazeera, 02 February 2014, <http://www.aljazeera.com/programmes/insidesyria/2014/02/geneva-talksprogress-towards-peace-2014211440978831.html>, (diakses 07 September 2014).

'Inside Free Syrian Army's Headquarters in Turkey', August 22, 2012, <http://www.almonitor.com/pulse/tr/politics/2012/08/inside-the-free-syrian-armys-turkishhq.html>, (diakses 10 Maret 2015).

'Kurdish People's Protection Unit (YPG)', <http://www.globalsecurity.org/military/world/para/ypg.htm>, (diakses 01 Desember 2015).

'Political Settlement becomes Obsolete after the Syrian Presidential Elections', June 18, 2014, <http://english.dohainstitute.org/release/92316048-a000-4b3e-90571c8323f8a8ca>, (diakses 15 Maret 2015).

'Russia, China veto UN resolution on sending Syria crisis to ICC', May, 23, 2014, <http://www.france24.com/en/20140522-russia-china-veto-un-resolutionsending-syria-crisis-international-criminal-court/>, (12 Maret 2015).

'Secret Turkish nerve center leads aid to Syria rebels', July 27, 2012, <http://www.reuters.com/article/2012/07/27/us-syria-crisis-centreidUSBRE86Q0JM20120727>, (diakses 10 Maret 2015).

'Synopsis of the Turkish Foreign Policy', <http://www.mfa.gov.tr/synopsis-of-theturkish-foreign-policy.en.mfa>, (diakses 08 Agustus 2014).

'Syria's Many Battlefields: Islamist Rebels Wage War Against the Kurds', 26 September 2013, <http://world.time.com/2013/09/26/syrias-many-battlefields-islamistrebels-wage-war-against-the-kurds/>, (diakses 19 April 2014).

'Turkey's Interest in Syrian War', 2014, The Caspian Report, <http://www.youtube.com/turkey's-interest,-in-syrian-war/the-caspianreport/>, (diakses 19 April 2014).

'Turkey's Role in Middle East', 2014, Talk to Aljazeera, <http://www.aljazeera.com/talk-to-aljazeera>, (diakses 19 April 2014).

'Turks Grant Recognition to Coalition of Syrians', November 15, 2012, <http://www.nytimes.com/2012/11/16/world/middleeast/turkey-recognizesnew-syrian-rebel-group-as-legitimate-leader-of-syria.html>, (diakses 10 Maret 2015).

'Will elections in Syria make any difference?', Inside Syria Aljazeera, 26 April 2014, <http://www.aljazeera.com/programmes/insidesyria/2014/04/will-electionssyria-make-any-difference-2014426173429172730.html>, (diakses 07 September 2014).

Abdulla, Namo., 'The rise of Syria's Kurds', 23 January 2014, <http://www.aljazeera.com/indepth/opinion/2014/01/rise-syriakurds201412353941189707.html>, (diakses 09 Agustus 2014). 
Barbosa, Anne Laure., 'A Powerful Illusion: Syrian Kurds and the Challenges to Their Autonomy', 20 November 2013, <http://www.edinburghint.com/services/advisory/recent-analysis/a-powerfulillusion-syrian-kurds-and-the-challenges-to-their-autonomy/>, (diakses 31 Desember 2014).

Betts, Richard K., 'The Delution of Impartial Intervention', dalam Conflict After the Cold War; Arguments on the Causes of War and Peace, Second Edition, ed. Richard K. Betts, Pearson Education, Inc.,USA, 2004.

Caves, John., 'Syrian Kurds and the Democratic Union Party (PYD)', Backgrounder, December 06, 2012, USA, Institute for the Study of War, <https://www.understandingwar.org/sites/default/files/Backgrounder_SyrianK urds.pdf>, (diakses 25 Desember 2014).

Dettmer, Jamie., 'Syria Falls Apart: Kurds Declare Self-Rule, Assad Besieges Aleppo', 14 September 2013, <http://www.thedailybeast.com/articles/2013/11/14/ syriafalls-apart-kurds-declare-self-rule-assad-besieges-aleppo.html>, (diakses 19 April 2014).

Ergun, Doruk., 'Turkish Views on the Syrian Civil War', 21 January 2014, <https://www.aspeninstitute.it/aspenia-online/article/turkish-views-syriancivil-war>, (diakses 19 April 2014).

Galdini, Franco and Pishko Shamsi., 'Syria's Kurds and Turkey', <http://www.jadaliyya.com/pages/index/15078/syria\%E2\%80\%99s-kurdsand-turkey>, (diakses 19 April 2014).

Griffits, Martin., Lima Puluh Pemikir Studi Hubungan Internasional, Edisi ke-1, PT. Raja Grafindo Persada, Jakarta, 2001.

Hatem, Robert dan Mark Dohrmann., 'Ankara's Challenges: Turkey's Fix for the Kurdish Problem', dalam Middle East Quarterly, Fall 2013, Volume XX, Middle East Forum.

Ilgit, Aslı and Rochelle Davis., 'The Many Roles of Turkey in the Syrian Crisis', January 28, 2013, <http://www.merip.org/mero/mero012813>, (diakses 30 November 2014).

Kouskouvelis, Ilias I., 'Turkey, Past and Future: The Problem with Turkey's Zero Problems', dalam Middle East Quarterly, Winter 2013, Volume XX, Middle East Forum.

Mas'oed, Mohtar., Studi Hubungan Internasional; Tingkat Analisis dan Teorisasi, Pusat Antar Universitas-Studi Sosial Universitas Gadjah Mada, Yogyakarta, 1989.

Reeve, Richard., 'Geneva II: Prospects for a Negotiated Peace in Syria', 29 November 2013, <https://www.opendemocracy.net/opensecurity/richard-reeve/genevaii-prospects-for-negotiated-peace-in-syria>, (diakses 15 Maret 2015).

Roy, S.L., Diplomasi, Edisi ke-1, Rajawali Pers, Jakarta, 1991.

Soeprapto, R., Hubungan Internasional; Sistem, Interaksi dan Perilaku, PT. Raja Grafindo Persada, Jakarta, 1997. 